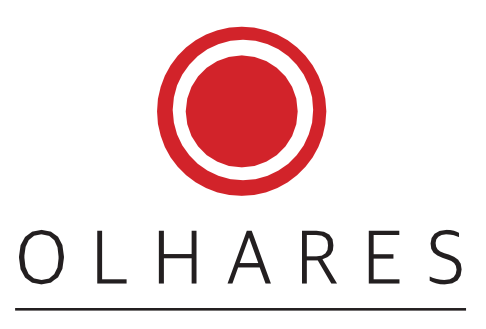

REVISTA DO DEPARTAMENTO DE EDUCAÇÃO - UNIFESP

\title{
PAULO FREIRE, BELL HOOKS E A CONSTRUÇÃO DE UMA PEDAGOGIA FEMINISTACRÍTICA
}

\author{
PAULO FREIRE, BELL HOOKS Y LA CONSTRUCCIÓNDE UNA \\ PEDAGOGÍACRÍTICAFEMINISTA
}

\section{PAULO FREIRE, BELL HOOKS AND THE CONSTRUCTIONOF AN CRITICALFEMINIST PEDAGOGY}

Silviana Fernandes Mariz Universidade da Integração Internacional da Lusofonia Afro-Brasileira (Unilab) silviana_mariz@unilab.edu.br

\begin{abstract}
Resumo: O presente artigo reflete sobre como bell hooks (1984; 1994) incorporou e transformou o pensamento de Paulo Freire em base teórico-metodológica para a construção e o fortalecimento de uma pedagogia crítica engajada numa perspectiva feminista, antirracista e decolonial. Para tanto, considerando o pensamento freireano como teoria itinerante (SAID, 1983; 2006), realizamos pesquisa em diferentes fontes, bibliográficas e audiovisuais, físicas e virtuais, publicadas principalmente nos Estados Unidos, a fim de estabelecer os marcos de aproximação entre Freire e hooks. Por outro lado, adotamos a prosopografia como método de investigação das características comuns compartilhadas por Freire e hooks em suas trajetórias como intelectuais públicos, situados no campo da Pedagogia Crítica Radical, com a finalidade de identificar conexões e zonas de contato em suas histórias de vida. Com isto, foi possível confirmar a teoria freireana como teoria itinerante, tendo em hooks uma potente leitora e articuladora de sua expansão para os estudos feministas.
\end{abstract}

Palavras-chave: Paulo Freire. bell hooks. pedagogia feminista

Resumen: Este artículo reflexiona sobre cómo bell hooks (1984; 1994) incorporó y transformó el pensamiento de Paulo Freire en base teórica y metodológica para la construcción y fortalecimiento de una pedagogía crítica comprometida con una perspectiva feminista, antirracista y decolonial. Considerando el pensamiento freireano como una teoría itinerante (SAID, 1983; 2006), realizamos una investigación en diferentes fuentes, bibliográficas y audiovisuales, físicas y virtuales, publicadas principalmente en Estados Unidos, para establecer la aproximación entre Freire y hooks. Por otro lado, adoptamos la prosopografía como método para investigar las características comunes que comparten Freire y hooks en sus trayectorias como intelectuales públicos, situados en el campo de la Pedagogía Crítica Radical, con el fin de identificar conexiones y zonas de contacto en sus historias de vida. Con ello, se pudo confirmar la teoría freireana como una teoría itinerante, teniendo en hooks a una poderosa lectora y articuladora de su expansión a los estudios feministas.

Palabras clave: Paulo Freire. bell hooks. Pedagogia feminista 


\begin{abstract}
This paper reflects on how bell hooks (1984; 1994) incorporated and transformed Paulo Freire's thought into theoretical and methodological basis for the construction and strengthening of a critical pedagogy engaged in a feminist, anti-racist and decolonial perspective. To this end, considering Freirean thought as itinerant theory (SAID, 1983; 2006), we conducted research in different sources, bibliographic and audiovisual, physical and virtual, published mainly in the United States, in order to establish the milestones of approximation between Freire and hooks. On the other hand, we adopted prosopography as a method to investigate the common characteristics shared by Freire and hooks in their trajectories as public intellectuals, situated in the field of Radical Critical Pedagogy, in order to identify connections and contact zones in their life histories. With this, it was possible to confirm Freirean theory as an itinerant theory, having in hooks a powerful reader and articulator of its expansion to feminist studies.
\end{abstract}

Keywords: Paulo Freire. bell hooks. Feminist pedagogy.

\title{
Introdução
}

Há praticamente 40 anos, o crítico literário Edward Said (1983) publicou artigo sobre o que ele denominou por teoria itinerante (traveling theory) ${ }^{1}$. Naquela ocasião, ao analisar a recepção da obra História e Consciência de Classe, de George Lukács, Said entendeu que certas teorias, ou ideias, adquirem a virtude de circular por lugares e épocas diferentes daquelas de onde emergiram como versão original. Tal circularidade, dependente de condições bastante espećficas (internas e externas à própria teoria), conduziria ao que ele chamou de domesticação teórica, ou seja, perda ou diminuição de suas forças de mobilização e transgressão que a levaria de revolucionária à normalizada porque rotinizada e institucionalizada através de seus usos e abusos por indivíduos e organizações sustentadores das hierarquias e do status quo que estruturam o campo científico (SAID, 1983).

Desse modo, quanto maior a distância temporal e cultural entre o seu ponto de origem e os de sua dispersão, maior será a "diminuição do tom de suas cores e a perda de sua força"; e, com isto, uma teoria, antes potencialmente rebelde, tende a se tornar "redução dogmática" de sua versão original, convertendo-se unicamente em fundamento teórico de algum campo científico (SAID, 1983). Refutando qualquer determinismo geográfico ou julgamento moral, Said, na verdade, entende que "a teoria é uma resposta a uma situação social e histórica especifica da qual faz parte uma ocasião intelectual" (1983, p. 237-238) e, nesse sentido, lugares não são determinantes dos tipos de teorias produzidas; mas, são

\footnotetext{
${ }^{1} \mathrm{Em} 2006$, Said revisitou suas formulações a respeito das teorias itinerantes. Analisando as formas pelas quais Fanon e Adorno se apropriaram do conceito de reificação, Said (2006), então, identifica como esses dois autores, de períodos históricos e contextos culturais nacionais totalmente diferentes dos de Lukács, conseguiram produzir interpretações valiosas e potentes a partir de sua incorporação.
} 
"irredutivelmente as primeiras condições" que "fornecem limites e aplicam pressões às quais cada escritor, dado seus próprios dons, predileções e interesses, responde." (idem, p. 238)

Dito isto, Said chama atenção para a necessidade de rejeitar o senso comum que professa ser uma apropriação teórica bem-feita aquela que se conforma à condição de "cópia escrava" (slavish copy), pois, em caso contrário, não passaria de exercício de "leitura equivocada" (misreading) ou "má interpretação" (misinterpretation). Para ele, portanto, o que se convencionou chamar de "leitura equivocada" nada mais é do que "parte de uma transferência histórica de ideias e teorias de um cenário para outro" inerente a todo processo de apropriação e releituras de uma teoria matriz (SAID, 1983, p. 237). Se as distâncias sociais, culturais e históricas suscitam o enfraquecimento ou o desbotamento em relação a sua versão original, por outro lado, elas possibilitam a emergência de interpretações criativas responsáveis por impedir que a teoria inicial seja endurecida e convertida em dogma, interditando assim reflexões críticas.

No caso específico das apropriações em torno da obra de Lukács, Said entende que é justamente pelo fato de seus leitores não conseguirem vivenciar o mesmo cenário social, cultural, político e histórico experimentado pelo filósofo húngaro é que surgirá uma rica variedade de interpretações em torno de sua obra, algumas menos críticas, outras mais - é o que ocorreu, por exemplo, com Raymond Williams sobre quem Said diz: exatamente "porque Cambridge não é a Budapeste revolucionária" e "porque Williams não é o Lukács militante" é que o sociólogo inglês pôde enxergar "os limites de uma teoria que começa como uma ideia libertadora, mas que pode tornar-se uma armadilha de si mesma." (SAID, 1983, p. 239)

A menção às análises de Said se justifica por assim entendermos o pensamento de Paulo Freire: como uma teoria itinerante que, ao viajar e aportar em contextos culturais nacionais bastante diferentes daquele de sua versão original, foi abraçada e albergada por vários intelectuais. A teoria freireana possui em seu autor um inédito ponto de origem reconhecido por incontáveis intelectuais de diferentes áreas, desde a Educação até a História, e de diferentes lugares, tanto nacionais quanto internacionais. Uma vez tendo se mostrado eficaz, transcorreu distâncias, alcançando contextos históricos e culturais completamente diversos de seu ponto de origem. Também foi apropriada de modos criativos, nem sempre apenas se acomodando aos novos cenários; mas, em muitas das vezes, sofrendo resistências e adquirindo interpretações criativas e críticas, adicionando-Ihe novas problemáticas e assim potencializando-o ainda mais. Por fim, justamente pelos novos usos 
e pela nova posição adquirida nos novos lugares e períodos históricos para onde viajou, foi transformada, enriquecida e expandida.

Particularmente, o seu livro Pedagogia do Oprimido, publicado em sua primeira edição em 1970 nos Estados Unidos, foi o responsável por apresentar ao mundo a teoria freireana para a educação, percorrendo os cinco continentes. Maders e Barcelos (2019, p. 385) avaliam que:

\begin{abstract}
Sem diminuir a importância do conjunto da vasta obra freireana, foi Pedagogia do Oprimido que abriu as portas das universidades e das escolas, bem como os olhos dos(as) educadores e educadoras do mundo para as ideias desse educador e cidadão brasileiro e latino-americano. (...). Com certeza antes de Freire chegar, pessoalmente, em muitos países lá já estava o livro Pedagogia do Oprimido sendo estudado, sendo referenciado, enfim, servindo de fonte para acalorados debates tanto na academia quanto fora dela nos movimentos sociais progressistas.
\end{abstract}

Nesse processo de dispersão, o pensamento de Paulo Freire, sem sombra de dúvidas, corresponde ao que Said (1983) nomeou de teoria itinerante que, uma vez em trânsito, não perdeu a sua força revolucionária; pois, à medida em que circulava mundialmente, foi sendo cada vez mais potencializada pelo acréscimo realizado por novas abordagens e autorias oriundas dos diferentes campos epistemológicos periféricos em relação ao centro hegemônico euramericano de produção mundial do conhecimento. Desde, pelo menos, a publicação de Pedagogia do Oprimido, a teoria freireana tem sido recepcionada por diferentes intelectuais, a exemplo de Ira Shor², Henry Giroux³ e Peter Mclaren ${ }^{4}$.

Frequentemente lembrados e citados, é preciso chamar atenção para o fato de que, não raramente, tem sido preservada certa tendência de dialogar e exaltar os leitores masculinos críticos de Freire (OLIVEIRA, SANTOS, 2018; GOMES, MULLER, 2019; JARDILINO, SOTO-ARANGO, 2020); mas, quase nunca o de dar visibilidade, às vozes femininas que também acolheram a teoria freireana, inclusive potencializando-a através de

\footnotetext{
2 Tendo publicado A Pedagogy for Liberation (1987) com Freire, Shor foi seu amigo pessoal e é considerado o primeiro intelectual a promover a obra freireana no contexto estadunidense. Em 1980, Shor publicou Critical Teaching and Everydaylife (1980) em que conduz suas análises sobre a política de admissão aberta (Open Admissions Politics) e o seu impacto na educação de estudantes-trabalhadores de origem imigrante em Nova York. Cf. SHOR, 1980; 1987.

${ }^{3}$ Giroux vem estabelecendo um amplo e profundo diálogo com Freire. Em Theory and Resistance in Education (1983), Giroux reserva um tópico inteiro votado a refletir sobre a noção freireana de alfabetização crítica. É nela que Giroux tributa à Freire o exemplo maior de um conjunto teórico-metodológico caracteristicamente afeito ao que é denominado de pedagogia crítica e radical. Cf. GIROUX, 1983.

${ }^{4}$ Assim como Shor e Giroux, Mclaren tem construído sua obra em torno de reflexões a partir da teoria freireana por ele também entendida como sendo exemplar de uma pedagogia crítica e radical. Em Life in Schools, Mclaren, apoiando-se em Freire, adota uma abordagem autobiográfica e autocrítica para refletir sobre a insuficiência da educação escolar centrada em conteúdos excludentes das culturas subalternas das classes trabalhadoras. Cf. MCLAREN, 1989.
} 
acréscimos ou mesmo de correções. É o caso de bell hooks que, situada nesse mesmo cenário histórico e intelectual, no entanto, tem sido negligenciada nas publicações que abordam as formas e autorias que se apropriam do pensamento freireano.

O fato de bell hooks não ter chegado a publicar em coautoria com Paulo Freire, muito provavelmente, deve ser acionado como forma de desculpar esse recorrente lapso; no entanto, ele é tão frágil quanto o argumento que tenta sustentar uma suposta incompatibilidade entre intelectuais feministas e Paulo Freire. Deste modo, apenas mais recentemente, tem surgido análises cotejando os estudos de Freire aos de hooks (MOURA, NERI, 2019); contudo, é imperativo assinalar que o próprio Freire destacava bell hooks cuja produção intelectual era vista, por ele, como importante para a reinvenção de sua teoria em contextos extra brasileiros (FREIRE, 1998).

Reconhecida, então, como uma importante escritora feminista afro-americana, hooks acolheu a pedagogia crítica de Paulo Freire, promovendo a sua aproximação ao feminismo e, assim, consequentemente contribuindo para a sua irradiação entre os círculos acadêmicos e populares feministas. No entanto, importa destacar, ela não o fez sem antes criticá-lo e nele apontar lacunas. Parafraseando Said, é exatamente porque os Estados Unidos não eram o Brasil da década de 1960 e porque hooks não era o Freire militante que ela pôde enxergar os limites da teoria freireana que trazia consigo uma ideia libertadora, mas que poderia se tornar uma armadilha de si mesma ao não enfatizar a participação feminina.

Dito isto, o presente artigo reflete, a partir do pensamento freireano como teoria itinerante (SAID, 1983; 2006), sobre os modos pelos quais bell hooks $(1984 ; 1994) 0$ incorporou e o transformou em base teórico-metodológica para a construção e o fortalecimento de uma pedagogia crítica numa perspectiva feminista, antirracista e decolonial. Para tanto, realizamos pesquisa em diferentes fontes, bibliográficas e audiovisuais, físicas e virtuais, publicadas principalmente nos Estados Unidos, com a finalidade de estabelecer os marcos de aproximação entre Freire e hooks ${ }^{5}$. Em termos metodológicos, adotamos a prosopografia 6 em nossa abordagem, através da "investigação das características comuns de um grupo de atores na história por meio de um estudo coletivo

\footnotetext{
${ }^{5}$ A pesquisa foi desenvolvida principalmente na internet, com o sistema de busca google acadêmico e repositórios de publicações especializadas como jstor, onde foram realizadas a seleção de textos em inglês e em português com base nas palavras-chave: "Paulo Freire + bell hooks". O mesmo procedimento foi feito no Youtube. Realizou-se também consulta a livros originais de Freire e hooks disponíveis no mercado editorial.

${ }^{6}$ A prosopografia "contém em seu interior a potencialidade para ajudar na recriação de um campo unificado além da frágil confederação de tópicos e técnicas zelosamente independentes. (...). [Ela] formaria o elo perdido entre a história política e a história social" (STONE, 2011, p. 133 - 134). Utilizada nos estudos das elites, com a microhistória foi adotada por estudos sobre as dinâmicas das organizações das classes populares e trabalhadoras. Cf. FERRARI, 2010.
} 
de suas vidas" (STONE, 2011, p. 115), cujas informações "são então justapostas, combinadas e examinadas em busca de variáveis significativas" (idem, ibidem) a fim de estabelecer o cotejo entre indivíduos e processos políticos gerais.

\section{A Pedagogia crítica ${ }^{7}$ freireana como teoria itinerante}

A trajetória de Paulo Freire como intelectual público global (TORRES, 2019) remonta ao tempo em que experimentou o exílio fora do Brasil. No entanto, a sua construção como intelectual em trânsito se iniciou no próprio país a partir do momento em que seu trabalho como docente e pesquisador da educação transcendeu as fronteiras culturais e políticas de Pernambuco, estado onde nasceu e cresceu.

A biografia de Paulo Reglus Neves Freire, ou simplesmente Paulo Freire, se confunde com a recente história política brasileira, tendo em vista que cada avanço e recuo do processo democrático nacional ao longo da segunda metade do século XX no país foi por ele acompanhado de perto, vivido profundamente e transformado em potente força interpretativa dos processos educativos. Nascido em 1921, Freire viveu sua juventude e as duas primeiras décadas de sua adultícia ainda em Recife, onde apesar das dificuldades financeiras, sobretudo, a partir dos seus 10 anos de idade, conseguiu concluir os estudos básicos e ingressar em uma faculdade pública, a de Direito, tradicionalmente ocupada pelos herdeiros das elites pernambucanas.

Se no atual cenário político nacional, o nome deste reconhecido filósofo da educação tem suscitado disputas e narrativas negacionistas quanto a sua incontornável importância para a Filosofia e a História da educação; por outro lado, é preciso continuar enfatizando a sua relevância. Já chamado de "Rousseau do século XXI" (BATTACHARYA, 2011) por uns e de "pai da pedagogia radical" por outros (MCLAREN, 1988), Freire, na verdade, destoa do tradicional perfil da maioria dos intelectuais brasileiros egressa de redes genealógicas de origem aristocrática ou industrial. Apesar de, a partir das primeiras décadas do século XX, as origens sociais da intelectualidade brasileira estabelecida em universidades e institutos cada vez mais se abrirem à participação de pessoas oriundas das classes trabalhadoras pobres, essa tendência, na verdade, só se amplia a partir do final do século (MICELI, 2001).

\footnotetext{
7 Para fins deste artigo, entendemos "pedagogia crítica" nos seguintes termos: "A pedagogia crítica, então, focalizaria o estudo do currículo não apenas como uma questão de autocultivo ou de imitação de formas específicas de linguagem e conhecimento. Ela enfatizaria formas de aprendizagem e conhecimento com o objetivo de fornecer uma compreensão crítica de como a realidade social funciona (...)" (GIROUX, 1988, p. 184)
} 
Paulo Freire, portanto, rompe com essa tradição elitista ao ter ingressado na prestigiada Faculdade de Direito de Recife, em 1943, aos 22 anos. Uma vez graduado em Direito, passou a acumular uma série de realizações profissionais: fundou, juntamente com outros intelectuais também de Recife, o Instituto Capibaribe; integrou, como membro, o Conselho Consultivo de Educação do Recife; assumiu, como diretor, a Divisão de Cultura e Recreação do Departamento de Documentação e Cultura da Prefeitura de Recife; doutorouse em Filosofia e História da Educação, com a defesa de sua tese "Educação e Atualidade Brasileira", tornando-se professor efetivo de Filosofia e História da Educação da Faculdade de Filosofia, Ciências e Letras da Universidade de Recife e, logo em seguida, Livre-docente na mesma instituição; e também foi indicado como Conselheiro Pioneiro do Conselho Estadual de Educação de Pernambuco (GADOTTI, 1998). À medida em que acumulava essas experiências, Paulo Freire conseguiu ampliar suas redes de contato e apoio.

Nesse sentido, importa destacar que a sua circulação como ativista em movimentos sociais pela educação popular se deu em um cenário político bastante específico, marcado, em Recife, pela chegada de Miguel Arraes $^{8}$, à época filiado ao Partido Social Trabalhista (PST), ao poder municipal com o apoio do Partido Comunista Brasileiro (PCB) bem como de vários movimentos sociais de caráter popular. Próximo de Paulo Freire, Arraes promoveu um amplo diálogo com sindicatos, ligas camponesas e associações comunitárias, sendo inclusive responsável pela criação de movimentos populares, a exemplo do Movimento de Cultura Popular (MCP) do qual Freire fez parte (SOUZA, 1989) ${ }^{9}$.

Além de Miguel Arraes, outra importante rede de contatos que permitiu a Freire conquistar espaços tanto na geografia nacional quanto na internacional foi a lgreja Católica, através de lideranças religiosas adeptas da Teologia da Libertação e atuantes nas Comunidades Eclesiais de Base (CEBs) e nas Pastorais Comunitárias. Engajado, então, em movimentos sociais apoiados, por um lado, por governos progressistas, a exemplo de Miguel Arraes, e por outro, pela lgreja Católica, Freire, uma vez no exilio, conseguirá através de agências de cooperação, sobretudo a partir da Europa, se movimentar e construir redes de apoio à educação popular em diferentes espaços que incluíram desde o Chile até os Estados Unidos, passando pelos países africanos (HADDAD, 2014).

\footnotetext{
8 Tendo sido prefeito entre os anos de 1960 e 1962, Arraes assumiu o governo do estado pernambucano ainda em 1962 com amplo apoio das classes trabalhadoras, em especial do campo. Considerado como um governo de esquerda, Arraes foi responsável pela ampliação dos direitos trabalhistas aos cortadores de cana, obrigando usineiros e proprietários de engenho a pagar-Ihes o salário-mínimo (LEVY, 1987).

${ }^{9}$ Com o golpe civil-militar de 1964, Arraes, assim como Freire, foi preso, conseguindo, após habeas corpus, ser exilado na Argélia de onde passou a editar o Boletim da Frente Brasileira de Informação que contou com a colaboração do próprio Paulo Freire (MEMORIAL DA DEMOCRACIA, 1969).
} 
Em 1964, em decorrência do golpe civil-militar, Paulo Freire deixa o Brasil e passa a viver primeiramente na Bolívia e depois no Chile, por lá ficando por aproximadamente 5 anos (MCLAREN, 1988; GADOTTI, 1998). Uma vez no Chile, Freire conseguiu expandir ainda mais os seus espaços de atuação, trabalhando como assessor do Instituto de Desarollo Agropecuário e do Ministério da Educação do Chile, além de ter se tornado consultor da UNESCO junto ao Instituto de Capacitacion e Investigacion em Reforma Agrária ${ }^{10}$.

É dessa época que Freire produz Ação Cultural para a Liberdade (Cultural Action for Freedom ${ }^{11}$ ) e Pedagogia do Oprimido (The Pedagogy of the Oppressed), publicadas apenas em $1970^{12}$ quando ele já se encontrava nos Estados Unidos a convite da Universidade de Harvard para assumir a vaga de professor visitante no Centro de Estudos do Desenvolvimento e da Transformação Social na Graduate School of Education (GSE). Convidado a permanecer por dois anos, Freire acabou ficando por apenas 10 meses, alternando a sua rotina acadêmica entre conferências e seminários ${ }^{13}$.

As duas obras logo se tornaram referência para os estudos sobre alfabetização e letramento numa perspectiva histórico-social crítica. Ambas repercutiram entre estudantes e docentes nos Estados Unidos, sobretudo entre quem estava situado no contexto de debates sobre os impactos da colonização. No caso específico de Pedagogy of the Oppressed, ela se "tornou-se um divisor de águas para educadores radicais dentro das escolas, comunidades e organizações trabalhistas que estavam lutando para trazer mudanças sociais para a saúde pública, para a assistência social e para as instituições educacionais de todo o país." (DARDER, BALTONADO, TORRES, 2003, p. 06), e é nesta obra que Freire aprofunda suas reflexões e as enrobustece, conferindo-lhes uma profundidade e potência teóricas a ponto de finalmente deixarem de ser um "método" para tornarem-se uma "teoria".

A teoria freireana de educação, assim conhecida como epistemologia na maioria das universidades e dos centros de estudos e pesquisas americanas onde aportou, passou a integrar os currículos dos cursos de graduação, não apenas os da área da educação, mas

\footnotetext{
10 É dessa época, 1969, que Freire publica La Educación como Práctica de La Libertad, além de Extensión o Comunicación em que reflete, de modo pioneiro, sobre a extensão universitária como prática de "invasão cultural" ao não estabelecer vínculos dialógicos com as comunidades envolvidas.

11 Publicado na Harvard Educational Review, dividido em duas partes: The Adult Literacy Process as Cultural Action for Freedom (Parte I) e Cultural Action and Conscientization (Parte II), o artigo dialogava abertamente com os manuscritos originais de Pedagogia do Oprimido em português, de 1968, que também foram publicados em 1970 na forma de livro.

12 Em 1967, Freire já havia estado nos Estados Unidos, como professor convidado, para cumprir com uma agenda de conferências e seminários sobre educação, popular e engajada, promovida por diferentes universidades de vários estados americanos. Cf. MCLAREN, 1988.

${ }^{13}$ Segundo Mclaren, Freire "de abril de 1969 a fevereiro de 1970, morou em Cambridge, Massachussetts, dando aulas sobre suas próprias reflexões na Universidade de Harvard, como professor convidado." (MCLAREN, 1988, p. 42).
} 
também os de filosofia. Principalmente Pedagogy of the Oppressed fará com que Freire seja "considerado por muitos como o filósofo educacional mais influente no desenvolvimento do pensamento e da prática pedagógica crítica." (DARDER, BALTONADO, TORRES, 2003, p. 06), tendo em vista que o "seu pensamento influenciou amplamente a teoria pós-colonial, os estudos étnicos, os estudos culturais, a educação de adultos, bem como as teorias de alfabetização/escolarização, de linguagem e de desenvolvimento humano" (idem, ibidem).

Concebendo a educação como uma ação cultural para a liberdade, Paulo Freire, no entanto, já havia antecipado essa abordagem em Cultural Action for Freedom (1970a), quando oferece uma crítica contundente à concepção tradicional de teoria que

\footnotetext{
não percebe a educação em geral e a alfabetização de adultos em particular como um ato de conhecimento. Ao contrário, ela reduz a prática da educação a um complexo de técnicas, ingenuamente consideradas neutras, por meio das quais o processo educacional é padronizado em uma operação estéril e burocrática. (FREIRE, 1970a, p. 205).
}

Deste modo, Freire entende a educação como um ato de conhecimento e não de memorização, em que o pensamento e a linguagem não podem ser compreendidos numa perspectiva de oposição binária, mas sim como "constituídos através de uma relação dialética entre o sujeito e sua realidade histórica e cultural concreta" (FREIRE, 1970a, p. 205). Utilizando-se da comparação com o processo digestório, ele critica a concepção tradicional do conhecimento em que se costuma entender a educação como um conjunto de operações meramente orgânicas e mecânicas, em que a consciência dos estudantes, como se fosse um estômago, não passaria de um espaço vazio a ser preenchido aleatoriamente.

Para Freire, então, a aquisição de conhecimento só pode ocorrer, profunda e verdadeiramente, se for situada na realidade dos estudantes para que assim seja possível a sua conscientização. Logo, é impossível educar se não for pela via do diálogo com a realidade do outro entendido também como sujeito do processo. As análises freireanas, na Harvard Educational Review, são apresentadas sob a luz de algumas das reflexões do sociólogo brasileiro Guerreiro Ramos de quem se apropria da concepção de "exemplarismo" para criticar o que o próprio Freire chama de "cultura do silêncio". Sob os efeitos do colonialismo, a cultura forjada nas e pelas sociedades coloniais é a da alienação em que a própria sociedade é constituída como uma "sociedade objeto". Em Freire, portanto, a educação é, antes, um processo de conhecimento do mundo onde os sujeitos estão situados e é somente por este processo que é possível alcançar a liberdade como prática constituída na e pela teoria. 
Rejeitando a ideia de que suas reflexões corresponderiam tão somente à oferta de um "método de alfabetização", eficiente e a ser repetido e reproduzido de forma transplantada, Freire assim se apresenta:

\begin{abstract}
Em uma época no Brasil em que a "cultura do silêncio" estava sendo exposta pelo que é, comecei como homem do Terceiro Mundo, a elaborar não um método mecânico para a alfabetização de adultos, mas uma teoria educacional gerada no útero da própria "cultura do silêncio", uma teoria que poderia se tornar na prática não a voz da cultura, mas um dos instrumentos das vozes ainda vacilantes (FREIRE, 1970a, p. 208).
\end{abstract}

Muitas de suas análises críticas presentes em Cultural Action for Freedom (FREIRE, 1970a) foram retomadas e aprofundadas em Pedagogy of the Oppressed (FREIRE, 1970b) cuja primeira publicação através de uma casa editorial também ocorreu em 1970. Contando em sua apresentação com os manuscritos originais escritos em 1968 em português, ela rapidamente ganhou reedições e traduções para outros idiomas, percorrendo, assim, diferentes contextos culturais nacionais dos cinco continentes por onde tem viajado, sendo acomodada, apropriada, tomada de empréstimo, criticada, disputada e até mesmo negada, mas nunca ignorada, exatamente por sua profunda força teórica que entende a aquisição da leitura e da escrita, em particular, e a educação, em geral, como processos de compreensão e construção do mundo, ou seja, como linguagem política de estar no mundo.

Donaldo Macedo, um dos principais colaboradores e amigos de Freire, sintetiza bem os significados profundos de Pedagogia do Oprimido que repercutiram nos corações e nas mentes de pessoas oriundas dos mais diferentes continentes, incluindo aqueles, a exemplo de África, que na década de 1970 atravessavam um de seus mais importantes momentos históricos: as lutas de independência dos países ainda colonizados por Portugal, como era o caso de Cabo Verde. Para Macedo, a imensa importância de Pedagogia do Oprimido repousava exatamente na virtude de ter lhe fornecido uma linguagem de compreensão crítica das realidades políticas:

Lembro-me vividamente de meu primeiro encontro com Pedagogia do Oprimido como um jovem colonizado de Cabo Verde que vinha lutando com questões significativas de identidade cultural, ansiando por romper com o jugo do colonialismo português. A leitura da Pedagogia do Oprimido me deu uma linguagem para entender criticamente as tensões, contradições, medos, dúvidas, esperanças e sonhos "adiados" que fazem parte de uma existência cultural emprestada e colonizada. (MACEDO, 2005, p. 11, grifo nosso)

Adicionalmente, importa destacar que os Estados Unidos encontrados por Paulo Freire era um país marcado por contradições sociais e econômicas assustadoras e por 
demonstrações políticas hiperbólicas. Se por um lado havia o avanço das conquistas de vários direitos civis para diferentes populações politicamente minorizadas, por outro também haverá o incremento de movimentos de direita. De acordo com Nash (2006), é exatamente a partir da segunda metade do século XX que uma "nova direita", como força política representada em grupos defensores do liberalismo na economia e do conservadorismo nas relações sociais, ganhará força através de ações de organização interna e de proselitismo externo por meio da criação de institutos de pesquisa, enclaves universitários, editoras e revistas acadêmicas.

Tais estratégias, turbinadas pela entrada de grupos cristãos renovados e radicais em suas fileiras, visavam, sobretudo, a ampliação de seu alcance traduzida na forma de votos ganhos em favor do Partido Republicano, cada vez mais aberto ao ingresso de movimentos e indivíduos que advogavam a defesa de pautas reacionárias contrárias ao avanço das leis que asseguravam institucionalmente a conquista de direitos civis às pessoas historicamente marginalizadas, a exemplo das populações femininas, negras, imigrantes e homossexuais. É neste complexo contexto que bell hooks encontra Freire.

\section{Educando mulheres através de Paulo Freire: bell hooks e seu feminismo como educação popular.}

Apesar de oriunda de um dos mais poderosos centros de produção do conhecimento ocidental, bell hooks ainda assim compartilha com Freire algumas zonas de similaridade quando comparamos as suas biografias.

Nascido e criado em Pernambuco, outrora epicentro de um Nordeste açucareiro, profundamente marcado pela escravidão de populações indígenas, africanas e mestiças, além de fortemente patriarcal, o Recife de 1921, ano em que Freire veio ao mundo, já se encontrava muito longe de ser um lugar de hegemonia econômica e política, despontando ao longo da primeira metade do século XX como epítome da decadência generalizada que acometia as tradicionais aristocracias do açúcar no Brasil (SOUZA, 2019). Ainda que homem e branco, é possível, a partir de sua biografia, afirmar que poucos foram os privilégios obtidos por Freire a partir dessas duas variantes; ao contrário disso, após a morte paterna, viu a sua família cair numa pobreza tão intensa que o fez conhecer a fome como algo cotidiano em sua vida. Diante de tantos entraves sociais, enxergou na educação não mero dispositivo de ascensão social, antes fez dela instrumento daquilo que costumava chamar de "conscientização" (FREIRE, 1970a) e de libertação, tendo sido o seu prestígio social 
transbordamento de sua própria práxis como educador e filósofo da educação, sem, com isso, implicar em migração de classes sociais.

No caso de bell hooks, ainda que estadunidense, a sua filiação nacional, no entanto, é insuficiente para compreender com profundidade o seu lugar social ${ }^{14}$. Nascida e criada em Hopkinsville, no estado de Kentucky, ela cresceu numa porção dos Estados Unidos, ocupada longamente por povos originários que, assim como os que viviam no Nordeste brasileiro, tiveram como espólio da ocupação estrangeira a perda de suas terras, a cristianização em massa, e inclusive a sua redução numérica em decorrência da transmissão de doenças e do trabalho compulsório. Também profundamente marcado pela escravidão de populações negras, africanas e suas descendentes, Kentucky tem a sua história marcada pelos brutais refluxos da política escravista que predominou fortemente até mesmo após a abolição ocorrida em 1865, na forma dos linchamentos públicos e legalizados que só foram encerrados em meados do século XX(WRIGHT, 1990). Adicionalmente, o Kentucky de 1952, quando hooks nasceu, era herdeiro de um forte patriarcalismo e de certa decadência econômica se comparado com o restante do país que abraçava, mais e mais, o capitalismo comercial (hooks, 1994). Diante deste cenário, ela também enxergou na educação o caminho para sua emancipação como mulher negra que também conviveu durante boa parte de sua vida com restrições sociais e econômicas decorrentes da pobreza, do racismo e do heterossexismo patriarcal.

Apontar as aproximações entre as biografias de Freire e hooks é recurso não apenas para enfatizar as suas trajetórias, mas, sobretudo, para indicar as possíveis razões pelas quais fizeram com que ela se sentisse profundamente atraída pelos escritos freireanos, e a eles se conectasse de uma forma que, mesmo criticando-os desde uma perspectiva feminista, ainda assim os abraçasse no mais profundo cerne do seu ser (hooks, 1994, p. 49). Em seus próprios termos:

É o pensamento feminista que me capacita a fazer uma crítica construtiva ao trabalho de Freire (que eu precisava para que, como jovem leitora de seu trabalho, não absorvesse passivamente a visão de mundo apresentada) e, no entanto, há muitos outros pontos de vista a partir dos quais me aproximo de seu trabalho que me permitem experimentar seu valor, que tornam possível que esse trabalho me toque no âmago do meu ser. Ao conversar com feministas acadêmicas (geralmente mulheres brancas) que sentem que devem dispensar ou desvalorizar o trabalho de

\footnotetext{
${ }^{14}$ Adotamos a expressão "lugar social", a partir de Certeau quando entende a escrita como produção acadêmica que "se articula com um lugar de produção socioeconômico, político e cultural. (...). É em função deste lugar que se instauram os métodos, que se delineia uma topografia de interesses, que os documentos e as questões, que Ihes serão propostas, se organizam." (CERTEAU, 2011, p. 47)
} 
Freire por causa do sexismo, vejo claramente como nossas diferentes respostas são moldadas pelo ponto de vista que trazemos para o trabalho. Cheguei a Freire com sede, morrendo de sede (de modo igual ao do sujeito colonizado e marginalizado, que ainda não sabe como quebrar o status quo, que anseia por mudanças, que é carente e que está sedento), e encontrei em seu trabalho uma maneira de saciar essa sede. Ter um trabalho que promove a própria libertação é um dom tão poderoso que não importa tanto se o dom é falho. (...). O trabalho de Paulo tem sido água viva para mim (hooks, 1994, p. 49 - 50).

A apreciação feminista à pedagogia crítica, no entanto, não é inaugurada por bell hooks. Conforme ela mesma reconhece, várias outras feministas já alertavam para os limites não apenas da obra de Paulo Freire em específico, mas da pedagogia crítica radical como um todo (hooks, 1984; 1994).

É o caso de Elizabeth Ellsworth que, através da crítica conceitual de expressões como "empoderamento", via na pedagogia crítica um projeto utópico descolado da verdadeira face da realidade estudantil marcada concretamente por preconceitos de classe, de raça e, sobretudo, de gênero. Desta forma, Ellsworth compreendia a pedagogia crítica como mais uma forma de reproduzir opressões em sala de aula através da criação e recriação do que chamou de "mitos repressivos" (ELLSWORTH, 1989). Importa assinalar que Ellsworth, entretanto, não foi uma voz solitária entre as feministas estadunidenses a apontar as insuficiências da pedagogia crítica. Segundo Darder, Baltonado e Torres (2003, p. 16):

\footnotetext{
Numerosas críticas à pedagogia crítica têm sido enraizadas em visões feministas e articulações de identidade, política e pedagogia. Algumas das críticas mais significativas foram emitidas por estudiosas feministas notáveis como Elizabeth Ellsworth, Carmem Luke, Jennifer Gore, Patti Lather, e Magda Lewis. (...). Tem havido muita desconfiança e preocupação com o fracasso da pedagogia crítica em se engajar diretamente nas questões das mulheres, ancorada no contexto da experiência feminina e da construção do conhecimento. Como tal, a pedagogia crítica tem sido frequentemente acusada de desafiar as estruturas e práticas do patriarcado na sociedade a partir de uma lente míope e superficial.
}

No caso específico de hooks, a sua crítica em relação aos limites da obra freireana aparece publicamente pela primeira vez em Feminist Theory from Margin to Center publicado em 1984 nos Estados Unidos. Nele, a autora, na verdade, oferece uma ampla revisão crítica do próprio feminismo que considera equivocado em várias de suas pautas, sobretudo ao assumir uma agenda restritiva que não dialogava com a realidade de mulheres não-brancas, das classes pobres trabalhadoras, imigrantes e refugiadas, mas, principalmente, das afroamericanas. Partindo da crítica à Mística Feminina, de Betty Friedan, hooks avalia que é necessário um feminismo radical, não liberal e anticapitalista, que não reforce ideias de vitimização nas mulheres e que aponte para a construção de alianças entre mulheres e 
homens, negros e brancos, rumo à libertação em relação às opressões capitalistas transfiguradas na forma do racismo e do sexismo (hooks, 1984).

Em meio às suas observações sobre os rumos do feminismo, como movimento político-filósofico, no contexto de um capitalismo voraz traduzido em sua forma neoliberal, sobretudo nos Estados Unidos, hooks defende a aliança e a solidariedade entre homens e mulheres como estratégia de organização básica para combater os efeitos perversos desse modelo de sociedade. É neste cenário analítico que ela traz Paulo Freire à discussão, cotejando suas reflexões com a proposta de um feminismo mais radical e engajado na luta antirracista e decolonial, mas não sem antes apontar também as fragilidades do próprio pensamento freireano que se constituiu em escrita marcada pela ausência feminina. Situando-o entre outros intelectuais, hooks afirma:

\begin{abstract}
Infelizmente, não são apenas os politicamente ingênuos que demonstram uma falta de consciência de que as formas de opressão estão interrelacionadas. Muitas vezes, pensadores políticos brilhantes têm tido tais pontos cegos. Homens como Franz Fanon, Albert Memmi, Paulo Freire e Aimé Cèsaire, cujos trabalhos nos ensinam muito sobre a natureza da colonização, do racismo, do classismo e da luta revolucionária muitas vezes ignoram questões de opressão sexista em sua própria escrita. Eles falam contra a opressão, mas definem a libertação em termos que sugerem que apenas "homens" oprimidos é que precisam de liberdade. (hooks, 1984, p. 39)
\end{abstract}

Mais adiante, ela complementa se referindo especificamente à Paulo Freire e à Pedagogia do Oprimido como um texto que "tem ajudado muitos de nós a desenvolver a consciência política" (hooks, 1984, p. 40), mas cujo conteúdo apresenta "uma tendência a falar da libertação das pessoas como libertação masculina." (Idem, ibidem). Na verdade, ela avalia se tratar de obra importante, mas que opera a partir do uso de "linguagem sexista" cujo efeito é, de algum modo, o de colaborar para a sustentação e a perpetuação da opressão com base na diferença sexual ${ }^{15}$. Ainda assim, ao longo do livro, hooks não deixa de dialogar teoricamente com Freire, pois entende que suas limitações não devem implicar em descarte de sua teoria, mas sim em alerta para sua incompletude no que concerne às mulheres ${ }^{16}$.

Com efeito, o debate público mais consistente com o pensamento freireano só é estabelecido por hooks, uma década depois de Feminist Theory, quando ela lança Teaching

\footnotetext{
15 Interessante sublinhar o cuidado que hooks teve ao disponibilizar suas críticas em relação à obra freireana. Em nota de fim de texto, na página 166, ela faz questão de informar que "em uma discussão com Freire sobre este assunto, ele apoiou de todo o coração esta crítica do seu trabalho e me exortou a compartilhar isto com os leitores." (hooks, 1984, p. 166).

16 hooks, por exemplo, reafirma a necessidade de se constituir uma práxis feminista libertária, conforme "Paulo Freire definiu práxis" (hooks, 1984, p. 112), a fim de que se consolide uma "educação como 'a prática da liberdade' (para usar outra expressão de Freire)" (idem, p. 115).
} 
to Transgress, education as the Practice of Freedom, publicado originalmente em 1994. Nele, hooks ainda apresenta críticas ao pensamento freireano, chegando inclusive a adotar a questionável metáfora da "água suja" ao solicitar de suas/seus leitoras/res que "pensem neste trabalho [o de Freire] como água que contém um pouco de sujeira" (hooks, 1994, p. 50)17; contudo, no cômputo geral, é em Teaching to Transgress que ela apresenta a sua teoria e a sua prática feminista pedagógica profundamente informada pela teoria freireana.

Do subtítulo do livro ao seu conteúdo (principalmente o $4^{\circ}$ capítulo inteiramente dedicado a Freire ${ }^{18}$ ), é possível identificar a sua influência em bell hooks, mesmo quando ela dialoga com outras autorias que também a influenciaram. A partir de uma narrativa autobiográfica em que reflete sobre os principais acontecimentos que a marcaram e a ajudaram a se definir como intelectual negra, a exemplo de quando as escolas públicas nos Estados Unidos passaram a adotar turmas multirraciais, hooks aponta Freire como "um mentor e um guia" (hooks, 1994, p. 6). A identificação com a sua obra adveio do reconhecimento em Freire da mesma característica que ela enxergava em si mesma, a de ser "alguém que compreendia que o aprendizado pode ser libertador" (idem, ibidem).

Não há como indicar com total precisão quando e onde exatamente hooks entrou em contato com a obra de Paulo Freire, no entanto, é possível presumir, a partir de Teaching to Transgress (hooks, 1994), que, primeiramente, houve um contato virtual, provavelmente quando ela ainda era estudante de pós-graduação, e somente em um segundo momento, quando já estava prestes a publicar Teaching to Transgress é que realmente se conheceram pessoalmente. Em relação a esse primeiro encontro, hooks afirma sobre Freire: "este mentor e guia, que eu nunca havia visto em carne e osso, encorajaria e apoiaria meu desafio às suas ideias se ele estivesse verdadeiramente comprometido com a educação como a prática da liberdade." (idem, p. 6). Mais adiante, ela informa que "anos antes de conhecer Paulo Freire, eu havia aprendido muito com seu trabalho, aprendido novas maneiras de pensar a realidade social que eram libertadoras." (idem, p. 45)

Tendo realizado seus estudos superiores ao longo das décadas de 1970 e 1980, hooks provavelmente encontrou Freire pessoalmente durante seu doutorado na Universidade da California em Santa Cruz. Nessa mesma época, Freire se encontrava indo

\footnotetext{
17 hooks compara a relação de consumo da água entre as pessoas de países pobres e as de países ricos: "Para mim esta é uma experiência que corresponde muito à forma como os indivíduos privilegiados respondem ao uso da água no contexto do Primeiro Mundo. Quando você é privilegiado, (...), você pode desperdiçar recursos. (...) nossa capacidade de ver a água que passa pela torneira como impura é informada por uma perspectiva imperialista." (hooks, 1994, p. 50)

18 Trata-se do capítulo 4, intitulado "Paulo Freire", em que hooks, em um diálogo consigo mesma, apresenta o seu processo de aproximação, apropriação e crítica em relação à obra freireana. Cf. hooks, 1994 , p. 45 - 58.
} 
e vindo dos Estados Unidos para cumprir com diferentes agendas, desde residência acadêmica até visitas curtas para participações em simpósios e seminários. Trazer essa cronologia à tona é importante, por um lado, para compreendermos o processo de recepção e de circulação da teoria freireana nos Estados Unidos de modo geral, e, por outro, para entendermos a profundidade do debate que hooks estabelece com a teoria freireana.

Segundo hooks, o contato com a obra de Freire foi a principal ferramenta teórica que permitiu-lhe criticar a política de segregação racial nas escolas públicas estadunidenses, pois apesar de ter promovido a abertura para a existência de turmas multiculturais, esse processo, no entanto, foi marcado pela inserção de estudantes negras/os nas escolas frequentadas por jovens brancas/os onde inexistia a perspectiva de uma educação política e crítica com a qual ela estava acostumada. Ao contrário disso, hooks afirma que era costume entre as escolas para brancas/os a adoção do que ela aprendeu com Freire a nomear como "sistema bancário de educação" (banking system of education). Esse mesmo sistema também estava presente nas faculdades onde os próprios professores desestimulavam e eram "ativamente hostis à noção de participação estudantil" (hooks, 1994, p. 14). Assim ela diz:

\footnotetext{
Quando eu comecei a faculdade, o pensamento de Freire me concedeu o apoio que eu precisava para questionar o 'sistema bancário' de educação, essa abordagem da aprendizagem que é enraizada na noção de que todos os estudantes precisam fazer é consumir informação dada para eles por um professor e ser capaz de memorizá-la e estocá-la. Desde cedo, foi a insistência de Freire de que a educação poderia ser a prática da liberdade que me encorajou a criar estratégias para o que ele chamou de 'conscientização' na sala de aula. (idem, ibidem)
}

Para hooks, a tradição burguesa de educação estruturou um modelo de aprendizagem em que não apenas se valoriza a separação radical entre docente e discente, em que 0 primeiro fala e o segundo apenas escuta, como também foi responsável por introduzir uma perspectiva hierárquica de oposição entre mente e corpo, e, consequentemente, entre teoria e prática. Neste sentido, o trabalho mental e, portanto, a teoria estariam ambos acima, em termos de importância, do trabalho corporal e prático. Tal abordagem se consolidou nas salas de aula a partir da aplicação inegociável de um "sistema bancário de educação". Perceber essas dinâmicas enquanto ainda era estudante de faculdade quase levou hooks a abandonar os estudos, o que não ocorreu justamente por ela ter encontrado em Freire o apoio intelectual necessário para continuar: 
Meu compromisso de aprender me manteve frequentando as aulas. Ainda assim, porque eu não me conformava - eu não poderia ser uma estudante passiva que não questionava - alguns professores me tratavam com desdém. Eu estava pouco a pouco me distanciando da educação. Encontrar Freire em meio a esse distanciamento foi crucial para a minha sobrevivência como estudante. $O$ seu trabalho me ofereceu tanto um caminho para que eu compreendesse as limitações do tipo de educação que eu estava recebendo quanto me fez descobrir estratégias alternativas para o ensino e a aprendizagem. (hooks, 1994, p. 17)

Encontrar Freire pessoalmente, tendo a oportunidade de estudar com ele, fez aumentar ainda mais a sua admiração, pois, de acordo com hooks, era corriqueiro ter professores que costumavam repetidamente citá-lo durante as aulas, sem, no entanto, incorporar a sua teoria na forma de prática pedagógica. A oportunidade de dialogar pessoalmente com Freire fez com que hooks ficasse "'profundamente comovida por sua presença, pela forma como a sua maneira de ensinar exemplificou sua teoria pedagógica" (idem, p. 18).

Deste modo, para hooks, Freire também representou muito mais que o papel de um intelectual da educação, tendo sido ele "um dos pensadores cujo trabalho forneceu uma linguagem" (hooks, 1994, p. 46) que a "fez pensar profundamente sobre a construção de uma identidade em resistência" (idem, ibidem). Admitindo que muitas das passagens dos textos freireanos se tornaram um "mantra revolucionário" para ela, a exemplo da célebre citação "Não podemos entrar na luta como objetos para depois nos tornarmos sujeitos", hooks entende, então, que mais que professor e intelectual, Freire foi quem a ajudou a se redefinir como intelectual negra fazendo educação de resistência.

Um ponto de partida fundamental para compreendermos a apropriação que hooks faz da teoria freireana numa perspectiva feminista é evidenciar o lugar social de onde ela se elabora como intelectual: na condição de mulher negra, ela se definirá como feminista, mas a partir de uma abordagem crítica em relação ao próprio movimento feminista por ela considerado como restritivo em suas primeiras reivindicações políticas e teorizações filosóficas.

Em Feminist Theory (1984), hooks critica o fato de o movimento feminista, em suas origens, ter se constituído como formado por mulheres brancas oriundas da classe média estadunidense. Essa composição fez com que, por um lado, ele se desenvolvesse a partir de uma base política e intelectual marcadamente burguesa, cuja formação se caracterizou por muito tempo como liberal e com perfil de alta escolarização; e, por outro, "de costas" para outras mulheres (negras, latinas, pobres, trabalhadoras) (hooks, 1984, p. 01). Somados esses dois elementos, hooks afirma que "muitas mulheres participantes no movimento feminista contemporâneo possuem ensino superior" (hooks, 1984, p. 107) e tal fato fez com 
que, apesar da luta contra o sexismo nas instituições de ensino, não fosse questionada "profundamente a conexão entre a exploração sexista das mulheres nessa sociedade e o grau de educação feminina, incluindo a falta de habilidades básicas de leitura e escrita" (idem, ibidem). Segundo hooks:

\begin{abstract}
Os preconceitos de classe levaram as mulheres que organizavam o movimento feminista a simplesmente presumir que a teoria e as estratégias feministas seriam melhor disseminadas para as massas através de material escrito. O foco no material escrito, na verdade, impede muitas mulheres de aprender sobre o feminismo. (1984, p. 108)
\end{abstract}

Esse cenário levou à auto-organização de mulheres periféricas através da criação de diferentes coletivos feministas populares formados à margem de um movimento feminista hegemônico e elitista; contudo esses novos arranjos, possivelmente numa postura de diferenciação em relação às feministas com perfil acadêmico, se caracterizaram por adotar uma postura anti-intelectualista:

\footnotetext{
Os preconceitos de classe burguesa levaram muitas teóricas feministas a desenvolver ideias que têm pouca ou nenhuma relação com as experiências vividas pela maioria das mulheres, teorias que não são úteis para fazer a revolução feminista. Indignadas e irritadas com estas ideias, muitas mulheres descartam toda a teoria como irrelevante. (...). Com frequência, mulheres de cor ativas no movimento feminista são anti-intelectuais. (hooks, 1984, p. 112 - 113)
}

Essa cisão entre feministas com alta escolarização, em geral pesquisadoras acadêmicas, e aquelas com perfil de escolarização menor levou a uma disputa interna ao movimento feminista, apelidado por hooks de "cabo de guerra". Para ela, é esse "cabo de guerra que tem existido dentro do movimento feminista entre as feministas intelectuais e acadêmicas e as participantes que igualam educação com privilégio burguês e são ferozmente anti-intelectualistas" (hooks, 1984, p. 112) o motivo para que a educação não fosse tomada como pauta central da agenda feminista.

A partir dessa constatação, hooks entende que, antes de afirmar essas cisões internas ao movimento feminista, é imperativo a reorganização das pautas de sua agenda que deve necessariamente incluir a criação de programas de alfabetização para mulheres em que não seja promovida a visão dicotômica entre teoria e prática existente entre as feministas acadêmicas e os coletivos feministas populares. Para hooks, a existência desses grupos separados, por si só, já reforça a oposição e suposta incompatibilidade entre teoria e prática; sendo preciso, então, a sua superação através da diversificação de estratégias de educação feminista, incluindo desde a adoção da comunicação verbal através de rodas de conversa e 
diálogos com uso de linguagem menos acadêmica como recurso para atingir audiências mais amplas, até a promoção de programas de alfabetização para mulheres.

É exatamente nesse ponto, o da defesa da criação de uma práxis feminista libertadora através da educação, que Paulo Freire é anunciado em suas reflexões:

\begin{abstract}
Encorajar as mulheres a lutar pela educação, para desenvolver seus intelectos, deve ser um objetivo primordial do movimento feminista. A educação como uma "prática de liberdade" (para usar outra frase de Freire) será uma realidade para as mulheres somente quando desenvolvermos uma metodologia educacional que atenda às necessidades de todas as mulheres. Estaé uma importante agenda feminista. (hooks, 1984, p. $114-115)$
\end{abstract}

Para hooks, portanto, só é possível pensar o feminismo como um movimento exitoso se ele puder se disseminar de forma capilarizada na sociedade e não apenas concentrado nas universidades e nos institutos de pesquisa. Essa capilaridade pressupõe, então, a promoção de um modelo de educação popular em que a produção da teoria ocorra como prática social que pode ser emancipadora, tanto para mulheres quanto para homens ${ }^{19}$ (hooks, 1994).

Como metodologia educacional, hooks entende que o feminismo deve abandonar suas elaborações teóricas excessivamente abstratas e complexas em favor da adoção de estratégias que dialoguem com a realidade de mulheres que sofrem em suas vidas diárias com questões vitais e urgentes, a exemplo da violência dentro e fora de casa bem como do acesso aos seus direitos reprodutivos e a serviços de saúde de qualidade. Neste sentido, hooks propõe, por um lado, a comunicação verbal (e não somente a escrita) e, por outro, o testemunho e a experiência pessoal como recursos geradores de debates e trocas teóricas entre docentes e estudantes. Em seus próprios termos, hooks afirma:

\footnotetext{
Refletindo sobre meu próprio trabalho na teoria feminista, acho a escrita mais significativa quando convida os leitores a se engajarem na reflexão crítica e a se engajarem na prática do feminismo. Para mim, esta teoria emerge do concreto, de meus esforços para intervir criticamente em minha vida e na vida dos outros. Isto para mim é o que torna possível a transformação feminista. O testemunho pessoal, a experiência pessoal, é um campo tão fértil para a produção da teoria feminista libertária, porque ela geralmente forma a base de nossa elaboração teórica. (hooks, 1994, p. 70)
}

\footnotetext{
19 A defesa de um feminismo capilarizado, ou massificado (para usar os termos da própria hooks), será retomado, posteriormente, na obra Feminism for Everybody: passionate politics em que discute com mais leveza e simplicidade algumas de suas críticas já abordadas em Feminist Theory. Cf. hooks, 2000.
} 
Em sua trajetória intelectual, hooks sempre admitiu que seu encontro com Paulo Freire permitiu não apenas enxergar os limites da própria teoria freireana, mas também as restrições internas ao feminismo como movimento político-filosófico. Se em Freire, ela enxergou a ausência feminina na proposição de um projeto de educação popular emancipadora; nas feministas, sobretudo nas ocidentais vinculadas ao circuito de produção acadêmica euroamericana, hooks, através das lentes freireanas, identificou no elitismo e nos vieses de classe os principais obstáculos para que o feminismo seja de fato amplamente abraçado pelas mulheres.

\section{Considerações finais}

Buscamos, neste artigo, mostrar que a influência de Freire não se limitou à sua geografia nacional. Muito além dela, a sua teoria conseguiu se consolidar como uma teoria itinerante (SAID, 1983; 2006), pois apesar de situada no contexto de um Brasil em profunda crise econômica e política, a obra de Freire possui a virtude de dialogar com diferentes cenários culturais nacionais.

Conforme a caracterização elaborada por Said $(1983 ; 2006)$ ao refletir sobre as teorias itinerantes, a teoria freireana não se construiu como dogma, o que lhe permitiu ser acessada e modificada de acordo com cada realidade para qual era destinada como ferramenta analítica. Longe de se constituir como "farsa" ou "doutrinação", conforme o querem alguns de seus atuais detratores no Brasil, Freire é "água vívida" (hooks, 1994).

A emergência de autorias periféricas, a exemplo de bell hooks (1984; 1994), foi responsável por promover uma apropriação do pensamento freireano sem incorrer em sua adoção automática e submissa, indo além que uma mera "cópia escrava". Longe disso, o seu compromisso com uma pedagogia radical não se deu sem resistência e crítica à Freire.

É exatamente nessa perspectiva que ocorreu o diálogo entre bell hooks e a obra freireana que é potencializada pela força político-filosófica feminista. Aorecepcionar as ideias freireanas, ela apontou os limites de uma escrita que, se não excluía, com certeza diluía e assim invisibilizava experiências e vivências femininas. hooks certamente não foi a única a se apropriar dos escritos de Freire, mas, com certeza, na qualidade de intelectual negra e feminista, ela exerceu pioneirismo ao ousar questionar as ausências nos textos freireanos, ao mesmo tempo em que desafiou as diferentes correntes do feminismo então em voga, sobretudo nos Estados Unidos, que negavam aos homens participação em solidariedade às lutas feministas. 
Desse modo, a teoria freireana, em hooks, se constitui como dispositivo de análise crítica para repensar o feminismo a partir de novas bases que incluem o antirracismo, a crítica ao colonialismo e, principalmente, ao capitalismo. Tomando a liberdade de parafraseála quando afirma que foi o pensamento feminista que a capacitou a fazer uma crítica construtiva ao trabalho de Freire (hooks, 1994, p. 49), é possível afirmar também, em sentido complementar: foi o pensamento freireano que, em grande medida, capacitou hooks a fazer uma crítica construtiva ao trabalho de várias feministas engajadas na luta pelo fim da opressão sexista. Dito de outro modo, hooks foi responsável por uma dupla crítica intelectual ao oferecer cuidadosa leitura analítica e aditiva tanto às análises freireanas quanto aos estudos feministas, apontando potencialidades e limitações.

Evocar as reflexões de hooks sobre o pensamento freireano, mais do que salutar, é urgente, sobretudo no atual contexto de retrocessos de direitos acelerados e aprofundados pela crise sanitária em decorrência da atual pandemia de Covid-19 em que as mulheres vem sofrendo duros impactos relacionados à excessiva sobrecarga de trabalho, doméstico e extra doméstico; à violência de gênero com incremento no número de casos de feminicídio e de agressões físicas; e, por fim, o agravamento da pobreza, sobretudo, entre as mulheres negras (BIANCONI et al, 2020). Trazer bell hooks e Paulo Freire, de modo interconectado, é fundamental para pensarmos como voltar a avançar, através da educação, em meio a esse cenário.

\section{Referências}

BHATTACHARYA, Asoke. Paulo Freire: Rousseau of the Twentieth Century. Rotterdam; Boston; Taipei: Sense Publishers, 2011.

BIANCONI, Giulliana; FERRARI, Marilia; LEÃO, Natália; MORENO, Renata; SANTOS, Thandara; ZELIC, Helena. Sem parar: o trabalho e a vida das mulheres na pandemia. São Paulo: Gênero e Número; Sempreviva Organização Feminista, 2020.

CERTEAU, Michel de. A Escrita da História. Rio de Janeiro: Forense Universitária, 2011.

DARDER, Antonia; BALTODANO, Marta; TORRES, Rodolfo. The Critical Pedagogy

Reader. New York; London: RoutledgeFalmer, 2003.

ELLSWORTH, Elizabeth. Why doesn't this feel empowering? Working through the repressive myths of critical pedagogy. Harvard Educational Review. V. 59, n. 3, p. 297 325, 1989. 
FERRARI, Marcela. Prosopografia e História Política: algunas aproximaciones. Antíteses, v. 3 , n. 5 , p. $529-550$, jan.jun. de 2010.

FREIRE, Paulo. La Educación como Práctica de la Libertad. Santiago: ICIRA, 1969a.

FREIRE, Paulo. Extención o Comunicación. Santiago: ICIRA, $1969 b$.

FREIRE, Paulo. Cultural Action for Freedom. Harvard Educational Review. V. 40, Issue 2, Summer, 1970a, p. 205 - 225.

FREIRE, Paulo. Pedagogy of the Oppressed. New York: Herder and Herder, 1970b.

FREIRE, Paulo. Extensão ou Comunicação. Rio de Janeiro: Paz e Terra, 1985.

FREIRE, Paulo. Pedagogia do Oprimido. Rio de Janeiro: Paz e Terra, 1987.

FREIRE, Paulo. Prefácio. IN: MCLAREN, Peter; LEONARD, Peter; GADOTTI, Moacir (org.). Paulo Freire: poder, desejo e memórias da libertação. Porto Alegre: Artmed, 1998.

FREIRE, Paulo; SHOR, Ira. A Pedagogy for Liberation, dialogues on transforming education. Massachussets: Bergin \& Garvey Publishers, 1987.

GADOTTI, Moacir (org.). Paulo Freire, uma biobibliografia. São Paulo: Cortez, 1998. GIROUX, Henry. Theory and Resistance in Education: a pedagogy for the opposition. Massachusetts: Bergin \& Garvey, 1983.

GIROUX, Henry. Teachers as Intellectuals: toward a critical pedagogy of learning. Connecticut; London: Bergin \& Garvey, 1988.

GOMES, Walmir Marcolino; MULLER, Antônio José. Paulo Freire: do (re)exilio brasileiro às cátedras norte-americanas. Revista Pedagógica. Chapecó, v. 21, p. 395 - 412, 2019.

HADDAD, Sérgio. Paulo Freire e o papel das agências de cooperação europeias no apoio à educação popular no Brasil. Pro-Posições. V. 25, n. 3, p. 123 - 141, 2014.

hooks, bell. Feminist Theory from margin to center. Boston: South End Press, 1984.

hooks, bell. Teaching to Transgress: education as the practice of freedom. New York, London: Routledge, 1994.

hooks, bell. Feminism for everybody: passionate politics. Cambridge: South End Press, 2000 .

JARDILINO, José Rubens Lima; SOTO-ARANGO, Diana Elvira. Paulo Freire and Critical Pedagogy: his legacy for a new pedagogy of the South. Revista Ibero-Americana de Estudos em Educação. Araraquara, v. 15, n. 3, p. 1072 - 1093, jul. / set. 2020.

LEVY, Henrique. Os acordos do campo de Miguel Arraes: notas sobre alianças de classe na história contemporânea. Clio Revista de Pesquisa Histórica. V. 10, n. 1, p. 123 -136, 1987. 
MACEDO, Donaldo. Introduction. IN: FREIRE, Paulo. Pedagogy of the Oppressed. New York; London: Continuum Publishing, 2005.

MADERS, Sandra; BARCELOS, Valdo. Paulo Freire - cidadão brasileiro, educador do mundo. Revista Pedagógica. Chapecó, v. 21, p. 378 - 394, 2019.

MCLAREN, Peter L. Culture or Canon? Critical Pedagogy and the Politics of Literacy. Harvard Educational Review. Vol. 8, n. 2, May 1988, p. 213 - 234. MCLAREN, Peter L. Life in Schools, an introduction to Critical Pedagogy in the Foundations of Education. New York: Longman, 1989.

MEMORIAL DA DEMOCRACIA. Exilados publicam notícias do Brasil. Novembro de 1969. Disponível em: http://memorialdademocracia.com.br/card/exilados-publicam-noticiasdo-brasil

MICELI, Sérgio. Intelectuais e Classes Dirigentes no Brasil (1920-45). IN: MICELI, Sérgio (org). Intelectuais à Brasileira. São Paulo, Companhia das Letras, 2001, p. 69-291.

MOURA, Adriana Dias de; NERI, Isabell Theresa Tavares; LOBATO, Vera Lúcia de Cristo. Por uma educação feminista na Amazônia: diálogos entre Paulo Freire e Bell Hooks.

Revista Amazốnida. V. 4, n. 1, p. 1 - 20, 2019.

$\mathrm{NASH}$, George H. The Conservative Intellectual Movement in America since 1945. Willmington: Intercollegiate Studies Institute, 2006.

OLIVEIRA, Ivanilde Apoluceno de; SANTOS, Tânia Regina Lobato dos. Paulo Freire na América Latina e nos Estados Unidos: cátedras e grupos de pesquisa. Revista Educação em Questão. Natal, v. 5, n. 8, p. 106 - 139, dez. / jun. 2018.

SAID, Edward. Traveling Theory. IN: SAID, Edward. The world, the text, and the critic. Cambridge: Harvard University Press, 1983, p. 226 - 247.

SAID, Edward. Reconsiderando a teoria itinerante. IN: SANCHES, Manuela Ribeiro (org.). Deslocalizar a Europa: Antropologia, Arte, Literatura e História na Pós-Colonialidade. Lisboa: Livros Cotovia, 2006, p. 25-2.

SHOR, Ira. Critical teaching and everyday life. Montreal; New York: Black Rose Books, 1980.

SHOR, Ira (ed). Freire for the Classroom, a sourcebook for Liberatory Teaching. Portsmouth: Heineman, 1987.

SOUZA, João Francisco. O dilema da alfabetização dos trabalhadores no Brasil. Tópicos Educacionais. V. 1, n. 2, p. 5 - 21, 1989.

SOUZA, Fábio Silva de. A cidade do Recife e a consciência da intelectualidade acerca do subdesenvolvimento brasileiro em meados do século XX. Revista Dimensões. V. 2, p. 315 - 332, jan. - jun. 2019.

STONE, Lawrence. Prosopografia. Revista de Sociologia e Política. Curitiba, v. 19, n. 39, p. 115 - 137, jun. 2011. 
TORRES, Carlos Alberto (ed.). The Wiley Handbook of Paulo Freire. New Jersey; Massachusetts: John Wiley \& Sons, 2019.

WRIGHT, George C. Racial Violence in Kentucky (1865 - 1940): lynching, mob rule and "legal lynching". Baton Rouge: Louisiana State University Press, 1990.

Recebido em: 09/08/2021

Aceito em: 24/09/2021 